\title{
Carotenoids in Mutants of Verticillium albo-atrum
}

\author{
BY L. R. G. VALADON \\ Department of Botany, Royal Holloway College \\ (University of London), Englefield Green, Surrey \\ AND J. B. HEALE \\ Department of Biology, Queen Elizabeth College \\ (University of London), Campden Hill, London, W. 8
}

(Received 6 July 1965)

\section{SUMMARY}

An orange mutant (M 5) obtained from a wild-type isolate of Verticillium albo-atrum by u.v. irradiation was found to contain phytoene, $\beta$-carotene, $\gamma$-carotene, neo-lycopene A, lycopene, neurosporaxanthin and four unidentified pigments. It is suggested that this simultaneous production of several carotenoid pigments by a hitherto colourless fungus may be regarded as a de-repression leading to the synthesis of a specific precursor in the pathway of carotenoid synthesis. Ultraviolet irradiation of $M 5$ gave a number of secondary colour mutants that were again analysed: M 5.1, M 5.3 and M 5.4 contained the same pigments as the original M 5 but in widely differing amounts. M 5.2 was colourless like wild type and contained only phytoene. M 5.5 formed a hitherto undetected pigment, torulene, lacked neo-lycopene $\mathbf{A}$ and lycopene and produced very little neurosporaxanthin. M 5 and M 5.5 were further investigated over an extended growth period in order to elucidate the sequence of carotenoid formation. The results are discussed in relation to possible hypotheses of carotenoid biosynthesis.

\section{INTRODUCTION}

The pathway leading to the synthesis of carotenoids is far from being completely understood. It has been suggested that since two molecules of farnesylpyrophosphate $\left(\mathrm{C}_{15}\right)$ form squalene $\left(\mathrm{C}_{30}\right)$, two molecules of geranylgeranylpyrophosphate $\left(\mathrm{C}_{20}\right)$ could give rise to carotenoids $\left(\mathrm{C}_{40}\right)$. Similar reactions to those occurring during squalene formation may take place terminating in the formation of lycopersene, its $\mathrm{C}_{40}$ homologue. Lycopersene by dehydrogenation could give rise to phytoene and finally carotenoids. In support of this, Grob \& Boschetti (1962) identified lycopersene in Neurospora crassa, but later Davies, Jones \& Goodwin (1963) could not find this compound even though they worked with the same strain. Moreover, most workers have failed to demonstrate the presence of lycopersene in nature, e.g. Mercer, Davies \& Goodwin (1963), Beeler, Anderson \& Porter (1963), Anderson \& Porter (1962), and this has led to an alternative suggestion that the formation of phytoene occurs directly from two molecules of geranylgeranylpyrophosphate. More recently, however, Nusbaum-Cassuto \& Villoutreix (1965) have been able to obtain as much as $50 \mu \mathrm{g}$. of lycopersene per $\mathrm{kg}$. of fresh white carrots. 
As regards the subsequent production of carotenoids from the $\mathrm{C}_{40}$ precursor there are two general hypotheses. Porter \& Lincoln (1950) have proposed the following pathway of dehydrogenation from phytoene, based on the results of a study on various tomato crosses:

$$
\text { Phytoene } \rightarrow \text { Phytofluene } \rightarrow \zeta \text {-carotene } \rightarrow \text { neurosporene } \rightarrow \text { lycopene. }
$$

At that time, the exact structures of the intermediates were not known, but more recently results obtained by Anderson, Norgard \& Porter (1960) feeding $\left.{ }^{14} \mathrm{C}\right]$ mevalonate to ripening tomatoes have given support to the above pathway. Further, Beeler \& Porter (1962) showed that preparations of tomato plastids could convert phytoene to phytofluene. Earlier Zechmeister \& Koe (1954) had reported the isolation of certain cyclic carotenes as a result of the dehydrogenation of phytoene and phytofluene by $N$-bromosuccinimide. There seems to be more support for the formation of cyclic carotenes through neurosporene rather than through lycopene since the intermediates $\alpha$ - and $\beta$-zeacarotene have been identified in maize (Petzold, Quackenbush \& McQuistan, 1959), in Rhodotorula glutinis (Simpson, Nakayama \& Chichester, 1964) and the structure of $\beta$-zeacarotene determined by Rüegg et al. (1961). The proposed scheme is as follows:

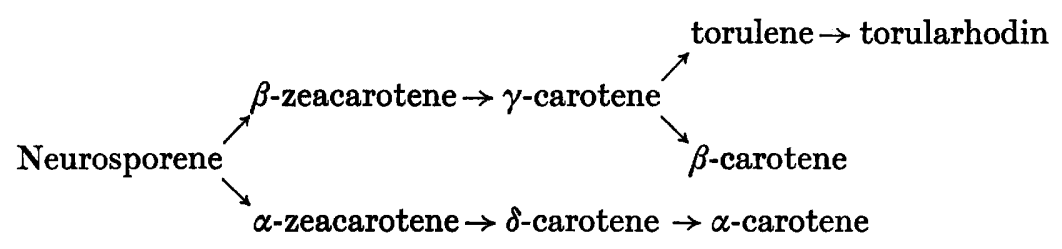

In fungi, however, an alternative hypothesis to that of Porter and Lincoln has been proposed, viz. that the $\mathrm{C}_{40}$ polyenes could be derived independently from a common precursor. Goodwin (1952), working with Phycomyces blakesleeanus, first suggested this when he reported that $\beta$-carotene was not formed at the expense of the phytoene series. Later, preliminary kinetic work by Goodwin and co-workers (Davies, Villoutreix, Williams \& Goodwin, 1963 suggested that $\beta$-zeacarotene, phytofluene, $\zeta$-carotene and neurosporene were formed from phytoene. Results obtained by Zalokar (1954) with Neurospora crassa under different conditions of light and oxygen in which $\zeta$-carotene, neurosporene and lycopene all appeared simultaneously support this second hypothesis.

Mutant studies have been used by several workers to examine the biosynthetic pathway of carotenoids in certain fungi. Bonner, Sandoval, Tang \& Zechmeister (1946) investigated seven $\mu . v$.-induced mutants of the red yeast Rhodotorula rubra and their results are consistent with the first (Porter-Lincoln) hypothesis. Villoutreix (1960) worked on u.v. mutants of another red yeast, $R$. mucilaginosa, and concluded that his results could not support the first but the second hypothesis. Haxo (1952), with mutants of the red bread mould Neurospora crassa, obtained results that agree equally well with both hypotheses.

In preliminary notes, Valadon \& Heale $(1964,1965)$ reported on an investigation the carotenoids of an orange coloured u.v. mutant (M 5) of Verticillium albo-atrum. This was apparently the first record of the simultaneous appearance of several carotenoids in a hitherto colourless fungus. In the present work a number 
of new colour mutants have been analysed in order to investigate the biosynthetic pathways of carotenoid production in this fungus.

In the study of coloured mutants of various organisms, changes have been reported in the balance of carotenoid synthesis. Villoutreix (1960) found that some of his mutants of Rhodotorula mucilaginosa had the same pigment composition but that the amounts varied. Three mutants of $R$. rubra obtained by Bonner et al. (1946) also gave the same picture and they found that these mutants could not be interpreted in any simple way. It has been suggested that the different amounts of carotenoids may reflect alterations in the timing of the various syntheses, and, therefore, two of the mutants in the present work were studied over an extended growth period.

\section{METHODS}

Ultraviolet mutants. The wild-type isolate of Verticillium albo-atrum Reinke \& Berthold used was originally isolated from wilted lucerne in Lincolnshire in 1962. The u.v. irradiation was done with a sterile distilled water suspension of conidia in an open Petri dish at a distance of $20 \mathrm{~cm}$. from a $2537 \AA$ 'Hanovia' bactericidal tube model 11 (with ozone reducing filter). An orange-pigmented colony, designated M 5, developed on plates of complete media spread with conidia irradiated at a dosage allowing for approximately $5 \%$ survival. Second-order mutants were produced in a similar manner using $\mathbf{M} 5$ as the parent source of conidia and they were selected by visual inspection of complete medium plates.

Extraction and identification of carotenoids. Cultures were grown on Wickerham's (1951) MYGP liquid medium on a reciprocating shaker at $20^{\circ}$ in the light. The pigments were extracted from 10-day-old cultures with methanol and transferred into diethylether by addition of water. The ethereal layer was evaporated under reduced pressure at $30^{\circ}$ and then taken up in methanol. This was saponified with $60 \%$ aqueous $\mathrm{KOH}$ overnight (Goodwin, 1955) and extracted with ethyl ether. The ethereal layer was washed with tepid water, freeze dried and the pigments taken up in about $2 \mathrm{ml}$. $n$-hexane. This was then chromatographed on a magnesium oxide + 'Celite' column $(1+1, v / v)$ and developed by washing with increasing concentrations of ether in $n$-hexane. In some of the cultures, the top brown orange band was strongly adsorbed to the powder and could be eluted by $0.5 \%$ glacial acetic acid in methanol.

The first colourless fraction which was eluted with purified $n$-hexane contained sterols, and these were removed according to the method of Mercer et al. (1963). Phytoene was identified in this fraction by means of its spectrum in $n$-hexane $(\sim 272,284, \sim 294 \mathrm{~m} \mu)$. The coloured bands eluted with ether in $n$-hexane were evaporated to dryness, taken up in $n$-hexane and the spectra estimated using a Unicam SP 500 spectrophotometer. The absorption spectra of the carotenoids were also measured in carbon disulphide and in benzene, while those of the fraction identified as neurosporaxanthin were also measured in acid methanol (1\% acetic acid) and in alkaline methanol ( $0.5 \% \mathrm{KOH})$. These were then compared with spectra of known carotenoids and their probable natures determined. To identify $\beta$-carotene, $\gamma$-carotene, neo-lycopene $\mathbf{A}$ and lycopene, respectively, a pure pigment was mixed with the unknown, co-chromatographed on activated alumina (Goodwin, 1954) eluted with ether in $n$-hexane and shown to be one and the same pigment when 
they ran as one band. In the case of torulene co-chromatography was carried out on a calcium hydroxide column using benzene as developer and for neurosporaxanthin on a sucrose column using $10 \%$ methanolinhexane as developer. Pure $\beta$-carotene, $\gamma$-carotene, neo-lycopene $\mathbf{A}$ and lycopene were obtained from Calendula officinalis (Goodwin, 1954); torulene from Rhodotorula rubra (Le Rosen \& Zechmeister, 1943) and neurosporaxanthin from Neurospora crassa (Zalokar, 1957).

\section{RESULTS}

M 5 was found to have phytoene, $\beta$-, $\gamma$-carotene, neo-lycopene A, lycopene, neurosporaxanthin and four unidentified bands, two of which were in too small a quantity to be identified further, and two other red and brown bands.

From the further irradiation of M 5 a number of secondary mutants were obtained and five of these (M 5.1 to M 5.5) were differently coloured and were analysed with respect to their carotenoid pigments (Table 1).

Table 1. Polyenes ( $\mu$ g./g. dry weight) of wild type and mutants of Verticillium albo-atrum after 10 days in culture

\begin{tabular}{|c|c|c|c|c|c|c|c|}
\hline \multirow[b]{2}{*}{ Pigments } & \multicolumn{7}{|c|}{ Appearance } \\
\hline & $\begin{array}{l}\text { Wild } \\
\text { type, } \\
\text { colour- } \\
\text { less }\end{array}$ & $\begin{array}{c}\text { M 5, } \\
\text { orange }\end{array}$ & $\begin{array}{c}\text { M 5.1, } \\
\text { dark- } \\
\text { orange }\end{array}$ & $\begin{array}{c}\text { M 5.2, } \\
\text { colour- } \\
\text { less }\end{array}$ & $\begin{array}{c}\text { M 5.3, } \\
\text { red- } \\
\text { orange }\end{array}$ & $\begin{array}{c}\text { M 5.4, } \\
\text { brown- } \\
\text { orange }\end{array}$ & $\begin{array}{l}\text { M 5.5, } \\
\text { pink- } \\
\text { red }\end{array}$ \\
\hline Phytoene & $\mathbf{2 8} \cdot \mathbf{4}$ & $20 \cdot 1$ & $12 \cdot 3$ & $21 \cdot 0$ & $18 \cdot 9$ & $16 \cdot 7$ & $26 \cdot 5$ \\
\hline$\beta$-Carotene & - & $23 \cdot 4$ & $28 \cdot 6$ & - & $21 \cdot 2$ & $6 \cdot 8$ & $24 \cdot 2$ \\
\hline$\gamma$-Carotene & - & $66 \cdot 4$ & 54.7 & 一 & $180 \cdot 5$ & $66 \cdot 9$ & $43 \cdot 3$ \\
\hline Neo-lycopene A & - & $11 \cdot 09$ & Trace & 一 & Trace & $24 \cdot 1$ & - \\
\hline Lycopene & - & $121 \cdot 9$ & $257 \cdot 4$ & - & $128 \cdot 1$ & $13 \cdot 5$ & 一 \\
\hline Torulene & - & - & - & - & - & - & $195 \cdot 0$ \\
\hline Brown band & - & $11 \cdot 3$ & $15 \cdot 6$ & 一 & 24.2 & $26 \cdot 3$ & Trace \\
\hline Red band & - & $22 \cdot 4$ & $18 \cdot 7$ & - & $22 \cdot 3$ & $18 \cdot 8$ & Trace \\
\hline Neurosporaxanthin & 一 & $178 \cdot 5$ & $\mathbf{2 5 5} \cdot 5$ & - & $261 \cdot 4$ & $193 \cdot 0$ & $\mathbf{5 \cdot 0}$ \\
\hline
\end{tabular}

Three coloured secondary mutants (M 5.1, M 5.3, M 5.4) contained the same carotenoids as the original mutant $M 5$ but in widely differing amounts. One mutant, M 5.5, formed a hitherto undetected pigment, torulene, lacked neolycopene $\mathbf{A}$ and lycopene and produced very little neurosporaxanthin. M 5.2 was very much like the wild type in its polyene content; it was colourless, containing only phytoene at similar amounts to that found in all the mutants and in the wild type.

The pigments of M 5 were analysed over a period of 21 days' growth (Fig. 1). Phytoene was estimated at $21 \cdot 7 \mu \mathrm{g} . / \mathrm{g}$. dry weight at 6 days, dropped to a minimum of $10.04 \mu \mathrm{g}$. after 18 days and rose to $17 \cdot 85 \mu \mathrm{g}$. at 21 days. $\beta$-Carotene, neo-lycopene $A$ and the two unidentified bands were all present at a concentration of approximately $20 \mu \mathrm{g}$./g. and did not vary very much over the period studied. $\gamma$-Carotene, lycopene and neurosporaxanthin were at a minimum after 6 days, rose to a peak at the 15th day and fell slightly after 21 days. The maximum for neurosporaxanthin was $245 \cdot 11 \mu \mathrm{g} . / \mathrm{g}$. after 18 days.

The pigments of M 5.5 were analysed over 18 days' growth (Fig. 2). The phytoene and $\beta$-carotene amounts were very much like those observed in $M$ 5. The two un- 
identified bands were present as traces up to the twelfth day and thereafter increased slightly to approximately $4 \mu \mathrm{g}$. $/ \mathrm{g}$. Neurosporaxanthin, however, was not found until the tenth day, and then only in traces, but later this reached a maximum of 25.24 $\mu \mathrm{g}$. by the sixteenth day. $\gamma$-Carotene was fairly high, 53.70 $\mu \mathrm{g}$. on the fourteenth day, but never as high as in M 5 (150 $\mu \mathrm{g}$. maximum). Torulene was the one pigment found in large amounts and it showed a similar curve to that of neurosporaxanthin for M 5, the peak in this case being $221 \cdot 26 \mu \mathrm{g}$. on the fourteenth day.

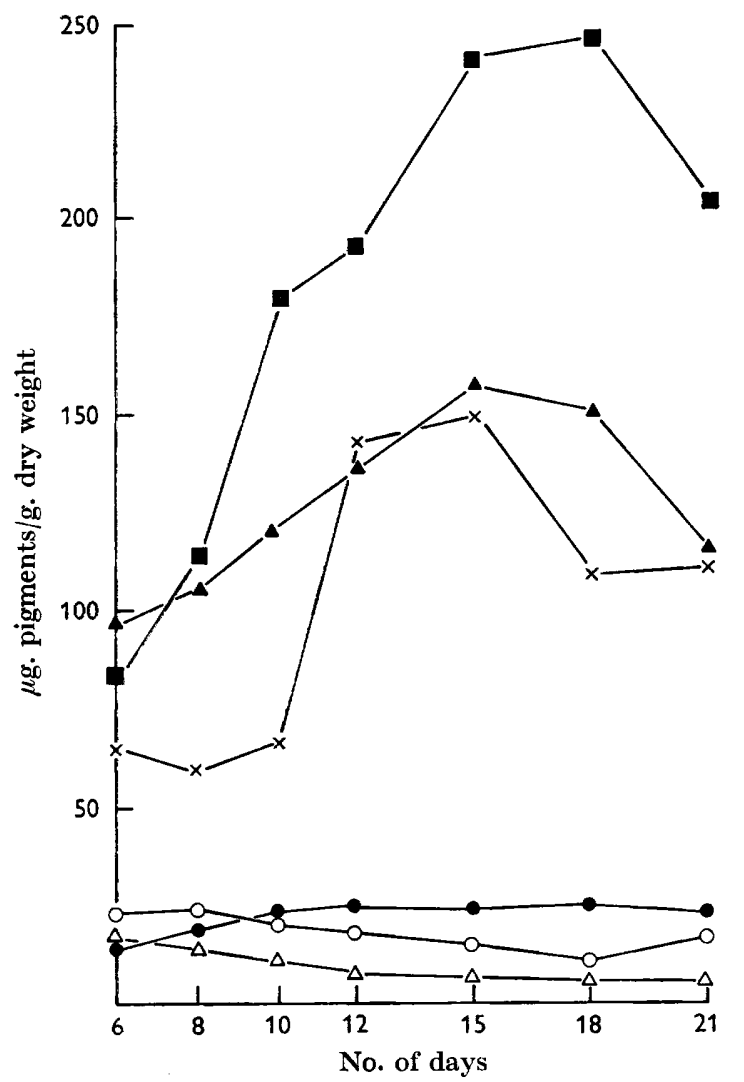

Fig. 1

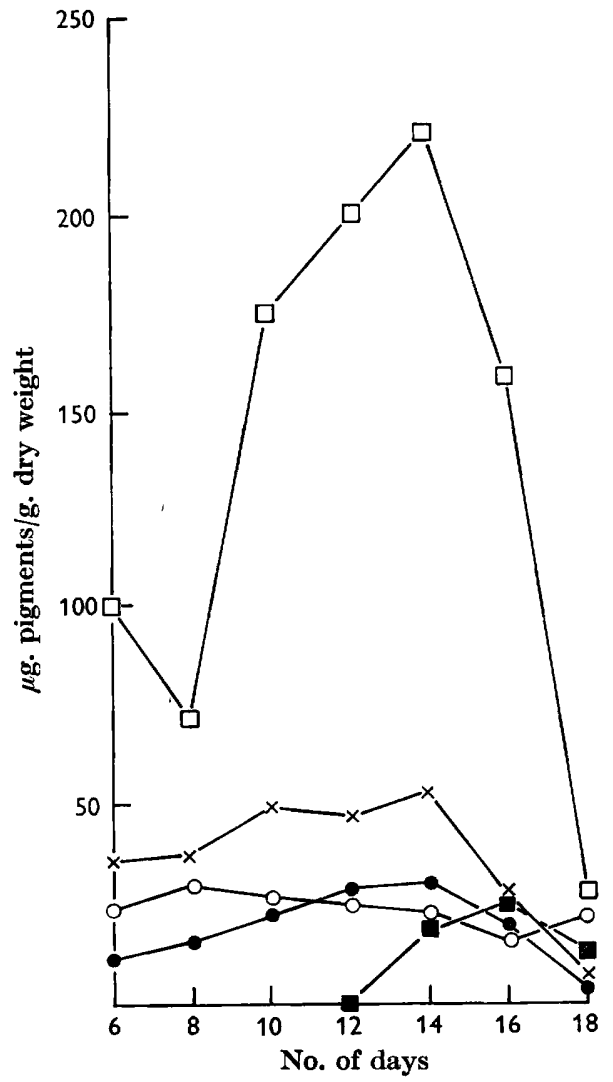

Fig. 2

Fig. 1. Changes in amounts of the different polyene pigments with age of the mutant $M 5$ of Verticillium albo-atrum. Phytoene, $\mathrm{O}-\mathrm{O} ; \boldsymbol{\beta}$-carotene, $-\gamma$-carotene, $\times-\times$; neo-lycopene $A, \Delta-\triangle$; lycopene, $\Delta-\Delta$; neurosporaxanthin, $\square-\square$.

Fig. 2. Changes in amounts of the different polyene pigments with age of the mutant M 5.5 of Verticillium albo-atrum. Phytoene, $\mathrm{O}-\mathrm{O} ; \beta$-carotene, $-\gamma$-carotene, $x-x$; torulene, $\square-\square$; neurosporaxanthin, $\square-\square$.

\section{DISCUSSION}

The simultaneous production of several carotenoid pigments by mutant $M$ 5, obtained in one step from a colourless wild-type Verticillium albo-atrum, is interesting and its interpretation may have some significance in our understanding of the genic regulation of carotenoid synthesis. It becomes necessary to explain the complete absence of carotenoids in the wild type, and also, since we assume that the mutation was operative at a single site, to explain how it could result in the formation of 
numerous pigments in M5. We suggest the simplest explanation is that the mutation occurred at a repressor site, which functions normally in the wild type to repress synthesis of a carotenoid pre-cursor ' $P$ '. The resulting loss of activity of the repressor in $\mathbf{M} 5$ thus led to the production of ' $\mathbf{P}$ ' (de-repression) which presumably then induced formation of the enzymes necessary for carotenoid synthesis. This derepression is now known to be readily reversible, since subsequent work has shown that colourless mutants, indistinguishable from wild type and similar to M 5.2, are frequently obtained by u.v. irradiation or nitrous acid treatment of $\mathbf{M} 5$ conidia (Heale, unpublished observation).

The study of M 5 over the growth period was made to establish whether its sequence of carotenoid synthesis reflected the variations of pigment composition shown by those mutants with a similar pattern of carotenoids, i.e. M 5.1, 5.3 and 5.4. If M 5.1 is compared with $M 5$ over 17 days when the amounts of phytoene and $\beta$-carotene are almost the same, one finds that $\gamma$-carotene is less abundant in M 5.1; neo-lycopene $A$ and lycopene are more abundant, while neurosporaxanthin is more or less the same in both. The lycopene level of $\mathrm{M} 5$ over 21 days is never as high as that of M 5.1. Similarly, M 5.3 and 5.4 can be compared with $\mathrm{M} 5$ and it can be seen that the differing amounts of carotenoids in these secondary mutants cannot be simply explained as being due to alterations in the sequence of their formation as observed in M 5.

B. H. Davies has shown that lycopene is found in young cultures of Rhizophlyctis rosea, while both lycopene and $\gamma$-carotene are found in older cultures (quoted by Goodwin, 1965). In M 5.5 (Fig. 2) torulene appeares to replace lycopene found in M 5, suggesting, that these two carotenoids may be linked in a synthetic pathway; there is evidence that $\gamma$-carotene is the precursor of torulene (Kayser \& Villoutreix, 1961; Simpson et al. 1964) and both lycopene and $\gamma$-carotene have neurosporene as their precursors. The presence of neurosporaxanthin in this mutant M 5.5 was interesting in that its synthesis was markedly delayed, only appearing after 14 days. Haxo (1952) obtained a somewhat similar result with mutants of Neurospora crassa which showed altered polyene composition, but in one of these there was a complete pigment block leading to elimination of neurosporaxanthin.

If one accepts the Porter-Lincoln hypothesis, one might expect that as phytoene is the precursor, it would be found in larger amounts when other carotenoids are not formed, for example, in the wild-type and in M 5.2. It seems, therefore, that the similar amounts of phytoene in the wild-type and mutants do not lend support to this hypothesis. However, precursor-product relationships are not always reflected in their quantities, or even in the detectability of the compounds involved (D. G. Anderson, personal communication) and so conclusions based on this type of evidence must be tentative only. On the other hand, the expected effect was shown to a certain extent by the two mutants M 5 and M 5.5 (when they were analysed over an extended period of growth) in that a slight fall occurred in the phytoene concentration during the synthesis of neurosporaxanthin. Zalokar (1954), working on the biosynthesis of carotenoids in Neurospora crassa, obtained a similar result and suggested that phytoene might be the precursor of neurosporaxanthin.

This research has been aided by grants from the Central Research Fund of the University of London. 


\section{REFERENCES}

Anderson, D. G. \& Porter, J. W. (1962). The biosynthesis of phytoene and other carotenes by enzymes of isolated higher plant plastids. Arch. Biochem. Biophys. 97, 509.

Anderson, D. G., Norgard, D. W. \& Porter, J. W. (1960). The incorporation of mevalonic acid-2-C ${ }^{14}$ and dimethylacrylic acid-3-C ${ }^{14}$ into carotenes. Arch. Biochem. Biophys. 88,68 .

Beeler, D. \& Porter, J. W. (1962). The enzymic conversion of phytoene to phytofluene. Biochem. biophys. Res. Commun. 8, 367.

Beeler, D., Anderson, D. G. \& Porter, J. W. (1963). Biosynthesis of squalene from mevalonic acid-2-C ${ }^{14}$ and farnesyl pyrophosphate-4, 8, 12-C ${ }^{14}$ by carrot and tomato enzymes. Arch. Biochem. Biophys. 102, 26.

Bonner, J., Sandoval, A., TANG, Y. W. \& Zechmeister, L. (1946). Changes in polyene synthesis induced by mutation in a red yeast (Rhodotorula rubra). Arch. Biochem. 10, 113.

Davies, B. H., Jones, D. \& Goodwin, T. W. (1963). The problem of lycopersene formation in Neurospora crassa. Biochem. J. 87, 326.

Davies, B. H., Villoutreix, J., Williams, R. J. H. \& Goodwin, T. W. (1963). The possible role of $\beta$-zeacarotene in carotenoid synthesis. Biochem. J. 89, 96 P.

Goodwin, T. W. (1952). Identification of the minor polyene components of the fungus Phycomyces blakesleeanus and a study of their synthesis under various cultural conditions. Biochem. J. 50, 550.

Goodwin, T. W. (1954). The carotenoids of the flower petals of Calendula officinalis. Biochem. J. 58, 90.

Goodwin, T. W. (1955). Carotenoids. In Modern Methods of Plant Analysis, 3, 282, ed. by K. Paech and M. V. Tracey. Berlin: Springer Verlag.

Goonwin, T. W. (1965). Chemistry and Biochemistry of Plant Pigments. London: Academic Press.

Grob, E. C. \& Boschetti, Z. (1962). Natural occurrence of lycopersin in Neurospora crassa. Chimia, 16, 15.

Haxo, F. (1952). Carotenoid formation by mutant strains of Neurospora crassa. Biol. Bull., Woods Hole, 103, 286.

KAyser, F. \& Villoutreix, J. (1961). Biosynthèse des caroténoïdes par Rhodotorula mucilaginosa. C.r. Séanc. Soc. Biol., Paris, 155, 1094.

Le Rosen, A. L. \& Zechmeister, L. (1943). The carotenoid pigments of the fruit of Celastrus scandens L. Arch. Biochem. 1, 17.

Mercer, E. I., Davies, B. H. \& Goodwin, T. W. (1963). Attempts to detect lycopersene in higher plants. Biochem. $J .87,317$.

Nusbaum-Cassuto, Era \& Villoutreix, J. (1965). Mise en évidence du lycopersène chez les végétaux supérieurs. C.r. hebd. Séanc. Acad. Sci., Paris, 260, 1013.

Petzold, E. N., Quackenbush, F. W. \& McQuistan, M. (1959). Zeacarotenes, new provitamins A from corn. Arch. Biochem. Biophys. 82, 117.

Porter, J. W. \& Lincoln, R. E. (1950). The mechanism of carotene biosynthesis. Arch. Biochem. 27, 390.

Rüegg, R., Schwieter, U., Ryser, G., Schuded, P. \& Isler, O. (1961). Synthesen in der Carotinoid-Reihe. Helv. chim. Acta. 44, 994.

Simpson, K. L., Nakayama, T. O. M. \& Chichester, C. O. (1964). Biosynthesis of yeast carotenoids. J. Bact. 88, 1688.

Valadon, L. R. G. \& Heale, J. B. (1964). Carotenoid pigments in a mutant strain of Verticillium albo-atrum Reinke \& Berthold. Nature, Lond. 202, 512.

Valadon, L. R. G. \& Heale, J. B. (1965). Biosynthesis of carotenoids in mutants of Verticillium albo-atrum Reinke \& Berthold. Fed. European Biochem. Soc. 2nd Meeting Abstracts. A. 70, p. 48.

VilloutreIX, J. (1960). Sur les caroténoĩdes d'une levure rouge:: Rhodotorula mucilaginosa (Jorg) Harrison. Nancy: Imprimerie Grandville.

Wickerham, L. J. (1951). Taxonomy of yeasts. Tech. Bull. U.S. Dep. Agric. 1029, 1. 
Zalokar, M. (1954). Studies on biosynthesis of carotenoids in Neurospora crassa. Arch. Biochem. Biophys. 50, 71.

ZaloKar, M. (1957). Isolation of an acidic pigment in Neurospora. Arch. Biochem. Biophys. 70, 568.

Zechmeister, L. \& KoE, B. K. (1954). Stepwise dehydrogenation of the colourless polyenes phytoene and phytofluene with $\mathrm{N}$-bromosuccinimide to carotenoid pigments. J. Am. chem. Soc. 76, 2923. 